\title{
Deep Membrane Proteome Profiling of Rat Hippocampus in Simulated Complex Space Environment by SWATH
}

\author{
Yun Wang, ${ }^{1,2}$ Peibin Qin, ${ }^{3}$ Jie Hong, ${ }^{1}$ Nuomin $\mathrm{Li}^{4}{ }^{4}$ Yongqian Zhang $\mathbb{D},{ }^{1}$ and Yulin Deng $\mathbb{D}^{1}$ \\ ${ }^{1}$ School of Life Science, Beijing Institute of Technology, China \\ ${ }^{2}$ Institute of Chinese Materia Medica, China Academy of Chinese Medical Sciences, China \\ ${ }^{3}$ Shanghai AB Sciex Analytical Instrument Trading Co., Ltd., China \\ ${ }^{4}$ Institute of Engineering Medicine, Beijing Institute of Technology, Beijing 100081, China
}

Correspondence should be addressed to Yongqian Zhang; zyq@bit.edu.cn and Yulin Deng; deng@bit.edu.cn

Received 25 February 2021; Accepted 10 May 2021; Published 27 May 2021

Copyright (C) 2021 Yun Wang et al. Exclusive Licensee Beijing Institute of Technology Press. Distributed under a Creative Commons Attribution License (CC BY 4.0).

\begin{abstract}
Despite the development and great progress in the field of space biology, the astronauts are still facing many challenges in space. The space environment in which astronauts stay includes microgravity, noise, circadian rhythms disorder, and confinement, which has deep effect both on the physiology and psychology of astronauts. It was reported that long-term flight could cause the astronauts' anxiety and depression. However, the underlying mechanism is not yet fully understood. Therefore, in the present study, the rat tail suspension model with noise, circadian rhythms, and confinement was employed to simulate complex space environment. We found that the rats exhibited the depressive-like behavior by the sucrose preference, forced swimming, and open-field tests. The membrane proteome of the rat hippocampus was investigated by "SWATH quantitation" technology both in control and simulated complex space environment (SCSE) groups. Out of 4520 quantified proteins, 244 differentially expressed membrane proteins were obtained between the SCSE and control rats, which were functionally enriched in a series of biological processes, such as translation, protein phosphorylation, brain development, endocytosis, nervous system development, axonogenesis, and vesicle-mediated transport. We found a reduction level of neurexin-2, the light, medium, heavy polypeptide of neurofilament, rab 18, synaptogyrin 1, and syntaxin-1A and an increase level of neuroligin-1, munc18, snapin, synaptotagmin XII, complexin-1, etc., which may play a key part in the development of depression. Furthermore, GSK-3 $\beta$ protein was upregulated in mass spectrometry, which was further validated by western blotting. The results of the study do the favor in designing the effective countermeasures for the astronauts in the future long-term spaceflight.
\end{abstract}

\section{Introduction}

During space travelling, astronauts may come across extreme environmental conditions such as microgravity, noise, radiation, confinement, and circadian rhythm disorder [1-3]. Previous studies focused mainly on physiological and psychological changes such as bone mineral loss [4-6], cardiovascular disruption [7-9], immune system malfunctioning [10-12], cognitive dysfunction [13-16], risky decision making, bad mood status, and high depression levels $[1,17,18]$ under the microgravity [19-21]. Few reports explore how the extreme complex space environment affects astronauts' physiological and psychological functions.

There are many significant limitations in conducting studies in space, including cost and opportunities along with high health risk. Earth-based simulation studies have been designed to investigate the physiological responses to microgravity. Tail suspension model has been widely used for the simulation of microgravity $[7,15,22-28]$ and approved by the National Aeronautics and Space Administration (NASA), Ames Research Center (ARC), and Institutional Animal Care and Use Committee on August 8, 2001 [29]. A variety of studies have investigated cognitive function under simulated microgravity (SM). 14-day SM-induced cognitive disorder is associated with cytomorphological changes and loss of hippocampus CA1 neurons [15]. The hippocampus is a key brain region for memory storage and retrieval. Previous studies using traditional 2DE coupled with MALDI-TOF have shown that 7-day SM induces the downregulation of structural and metabolic proteins [26]. Our previous study showed that SM increases SNARE-related proteins in the hippocampus, leading to impaired learning and memory 
function [30]. Moreover, the effects of long-term exposure (21 days) to SM on the expression of metabolic proteins and membrane proteins in the hippocampus were investigated [31,32]. Lots of evidences have shown that the hippocampus might be susceptible to microgravity.

Different from most of the previous studies, a device was developed to simulate the complex space environment on the ground. We used sequential window acquisition of all theoretical mass spectra (SWATH) technique to analyze expressional changes of hippocampus membrane proteins in Sprague-Dawley (SD) rats in response to simulated complex space environment(SCSE). SWATH is a newly developed data-independent acquisition (DIA) methodology, which can simply be explained as large-scale MRM combining the strength of regular shotgun proteomics [33]. It continuously fragments all the peptides with stepped $\mathrm{m} / \mathrm{z}$ windows. The resulting transition ions are matched to a spectral library obtained by shotgun proteomics and retention time correction and generate peptide/protein identification and quantification results. Previous studies have shown that SWATH not only provides precise label-free quantification on proteome scale [34] but also is successfully used for biomarker discovery and verification of esophageal squamous cell [35]. It is feasible and efficient for the large-scale precise quantification of rat hippocampus under SCSE.

\section{Materials and Methods}

2.1. Animal. All experiments were performed with adult, male SD rats $(220 \pm 20 \mathrm{~g}, 10$ weeks old $)$ supplied by the Experimental Animal Institute of the Medical Science Academy in Beijing, China. Rats were housed individually in cages in a room under $12 \mathrm{~h}$ light/dark cycle and had free access to food and water. The tail suspension model was applied to induce simulated microgravity as previously reported [23, $24,36,37]$. Thirty male SD rats were taken for three independent experiments. For each experiment, 10 rats were taken and divided into two groups. For SCSE, rats were kept suspending their bodies with their tails for 28 days according to previous reports $[23,24]$. Moreover, noise $(65 \mathrm{db}), 1.5 \mathrm{~h}$ light/dark cycle, and separate cages were ensured for SCSE. The control rats were kept in normal cages with free access to food and water. After 28 days of simulation, the rats were sacrificed by cardioperfusion. The hippocampus tissues were then dissected from the control and SCSE groups and preserved at $-80^{\circ} \mathrm{C}$ for further experiments. All experimental procedures were approved by the Ethics Committee of the Beijing Institute of Technology.

2.2. Behavioral Tests. Forced swim test (FST), sucrose preference test, and open-field test (OFT) were performed as previously reported [38-41]. Rats were divided into experimental groups based on their baseline sucrose intake. Too high or too low baselines were excluded from the experiment.

2.3. Isolation of Crude Membrane Fractions. The hippocampal proteins were prepared as previously reported [42, 43]. The tissue was homogenized with a Teflon-glass dunce homogenizer (ten strokes in total) in ice-cold buffer contain- ing $250 \mathrm{mM}$ sucrose, $50 \mathrm{mM}$ Tris- $\mathrm{HCl}(\mathrm{pH} 7.4), 5 \mathrm{mM}$ $\mathrm{MgCl}_{2}, 1.0 \mathrm{mM}$ dithiothreitol (DTT), $25 \mu \mathrm{g} / \mathrm{mL}$ spermine, $25 \mu \mathrm{g} / \mathrm{mL}$ spermidine, and a protease inhibitor mixture tablet (Roche Diagnostics, Germany). The mixture was centrifuged at $6,000 \times \mathrm{g}$ for $15 \mathrm{~min}$ at $4^{\circ} \mathrm{C}$ to remove nuclei, cell debris, and mitochondria. The supernatant was transferred to a new tube and centrifuged with high speed $(10,000 \times \mathrm{g}$ for $60 \mathrm{~min}$ ). The pellet was resuspended with $0.5 \mathrm{~mL}$ buffer (8 $\mathrm{M}$ urea, $10 \mathrm{mM}$ DTT, $1 \%$ TritonX-100, $50 \mathrm{mM}$ $\mathrm{NH}_{4} \mathrm{HCO}_{3}$ ), incubated on ice for $30 \mathrm{~min}$, and centrifuged at $16,500 \times \mathrm{g}$ at $4^{\circ} \mathrm{C}$ for $30 \mathrm{~min}$, and then, the supernatant was preserved. Finally, the protein concentration was determined by Bradford assay.

2.4. The Filter-Assisted Sample Preparation Digestion. The filter-assisted sample preparation (FASP) method was used to generate tryptic digests for subsequent LC-MS acquisitions. Dissolved membranes were processed by the FASP procedure using $10 \mathrm{kDa}$ MWCO filtration tubes (Sartorius). Each fraction extract $(400 \mu \mathrm{g})$ was reduced with $10 \mathrm{mM}$ DTT for $1 \mathrm{~h}$ at $37^{\circ} \mathrm{C}$ and alkylated with $50 \mathrm{mM}$ iodoacetamide (IAA) in the dark for $30 \mathrm{~min}$, subsequently. A total of $200 \mu \mathrm{L}$ of sample was added to a $1.5 \mathrm{~mL} 10 \mathrm{kDa}$ MWCO filtration tubes. Samples were centrifuged at $14,000 \times \mathrm{g}$ until an equal volume of the buffer was left on each filter. Then, the concentrate was diluted with $200 \mu \mathrm{L}$ of $8 \mathrm{M}$ urea in $50 \mathrm{mM}$ $\mathrm{NH}_{4} \mathrm{HCO}_{3}$ (UA solution) and concentrated again. The washing procedure was repeated twice in order to remove the majority of Triton X-100. Next, samples were washed three times with $200 \mu \mathrm{L}$ of $50 \mathrm{mM}$ ammonium bicarbonate to remove excess urea. Sequencing grade trypsin (Promega, USA) was added to each vial at 1:50 enzyme: substrate ratio and incubated for overnight at $37^{\circ} \mathrm{C}$. Peptides were collected by centrifugation at $14,000 \times \mathrm{g}$ in a clean $1.5 \mathrm{~mL}$ tube. Finally, peptide concentration was determined by BCA assay. Peptides were vacuum-dried prior to offline RP-RP analysis (CHRIST RVC 2-18 CDplus).

2.5. Offline RP-RP Analysis. The peptides were resuspended in buffer A (98\% water, $0.02 \%$ ammonium hydroxide $(\mathrm{pH}=10)$ and separated by an Agilent 1100 HPLC system with a Durashell column $(4.6 \times 250 \mathrm{~mm}, 5 \mu \mathrm{m}$, Agela $)$ at a flow rate of $0.7 \mathrm{~mL} / \mathrm{min}$. The linear gradient was $5 \%-8 \% \mathrm{~B}$ (98\% ACN, 0.02 ammonium hydroxide, $\mathrm{pH}=10)$ for $5 \mathrm{~min}$, followed by $8-22 \%$ for $25 \mathrm{~min}, 22-36 \%$ for $10 \mathrm{~min}$, and $36-80 \%$ for $5 \mathrm{~min}$. The gradient was then held at $80 \%$ for $5 \mathrm{~min}$ and finally at $5 \% \mathrm{~B}$ for another $10 \mathrm{~min}$. The elution was collected at every $1 \mathrm{~min}$ interval. The fractions were combined to 6 according to the UV spectroscopy and evaporated to dryness by SpeedVac (CHRIST RVC 2-18 CDplus).

2.6. LC-ESI-DDA. The high RP-fractionated peptides were measured with a nano-flow Tempo LC system (Eksigent) coupled to a TripleTOF 6600 mass spectrometer (AB Sciex). Samples $(5 \mu \mathrm{L})$ were loaded into a $200 \mu \mathrm{m} \times 0.5 \mathrm{~mm}(3 \mu \mathrm{m})$ C18 column (Eksigent trap column) and separated on $75 \mu \mathrm{m} \times 15 \mathrm{~cm} \mathrm{C18}$ analytical column packed with $3 \mu \mathrm{m}$ (Eksigent) at the flow rate of $300 \mathrm{~nL} / \mathrm{min}$. The mobile phase 


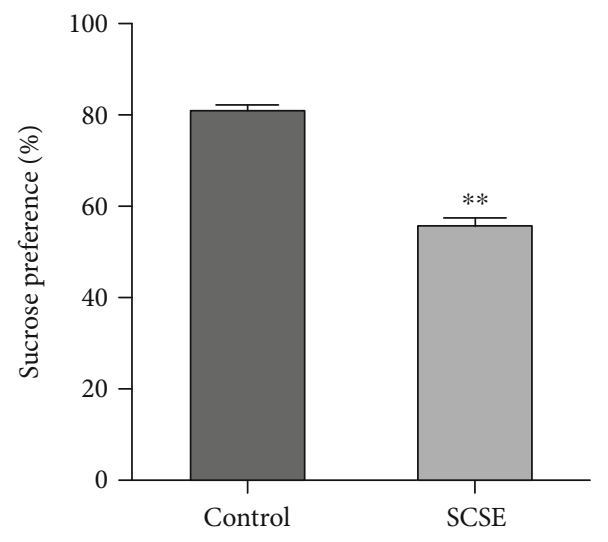

(a)

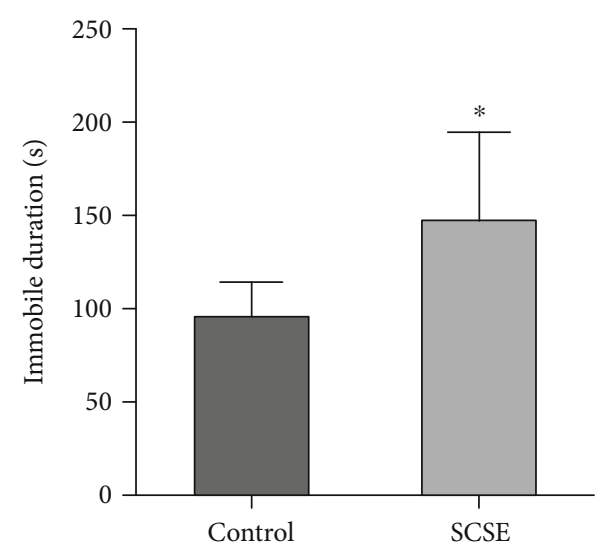

(b)

FIGURE 1: The sucrose preference test (a) and the forced swimming test (b) in the simulated complex space environment (control $n=15$, SCSE $n=15)$. Data are expressed as mean $\pm \mathrm{SD}$, and $p$ value was determined by an unpaired Student $t$-test. ${ }^{*} p<0.05$, vs. the control group. ${ }^{* *} p<0.01$.

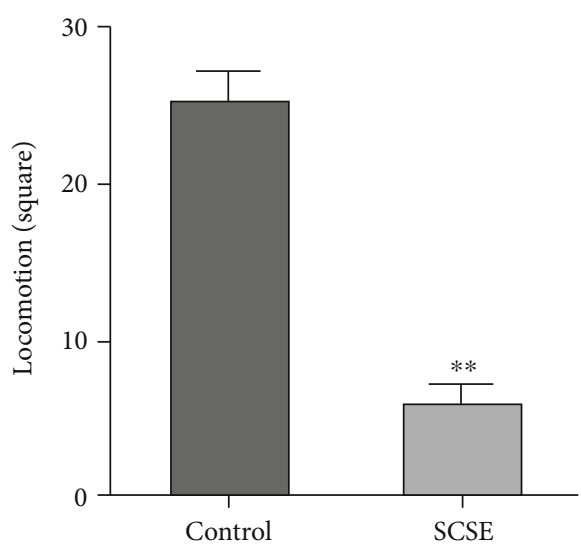

(a)

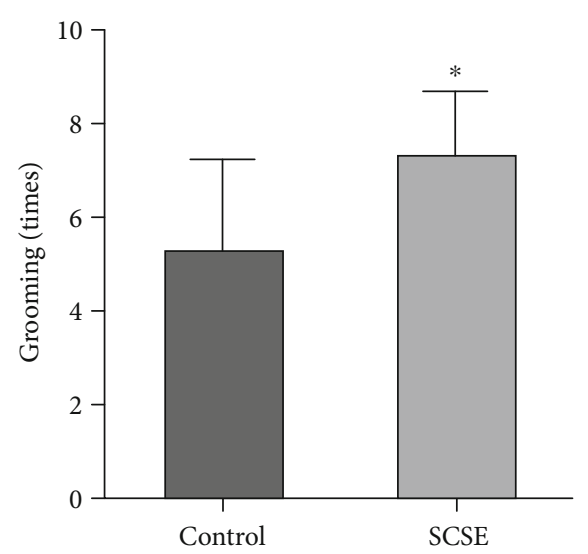

(d)

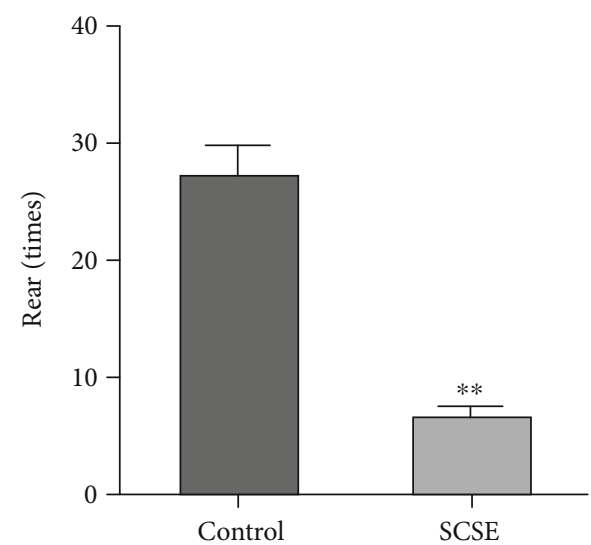

(b)

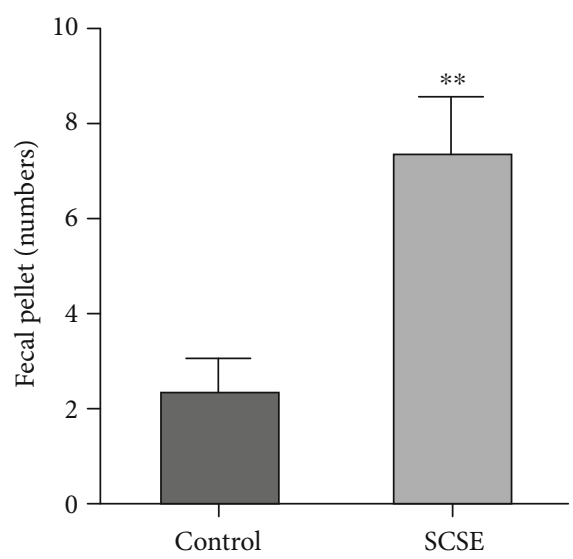

(e)

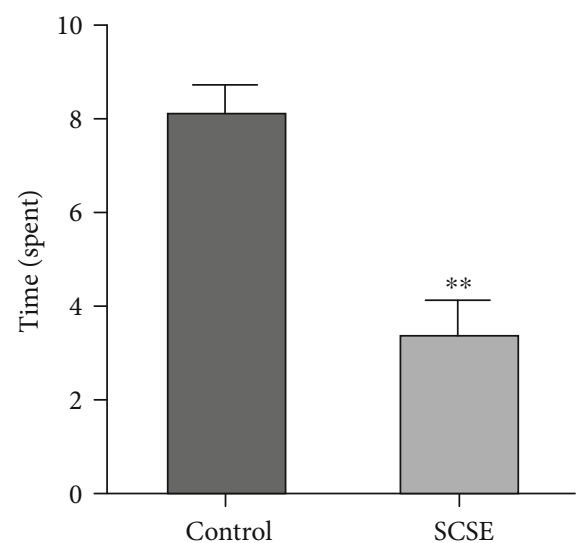

(c)

FIgURE 2: The open-field test in the simulated space environment: (a) the horizontal locomotion of model rats during the open-field test; (b) the time of rearing of model rats during the open-field test; (c) the time spent in the central during the open-field test; (d) the time of grooming during the open-field test; (e) the number of fecal pellets during the open-field test (control $n=15$, SCSE $n=15$ ). Data are expressed as mean $\pm \mathrm{SD}$, and $p$ value was determined by an unpaired Student $t$-test. ${ }^{*} p<0.05$, vs. the control group. ${ }^{* *} p<0.01$. 


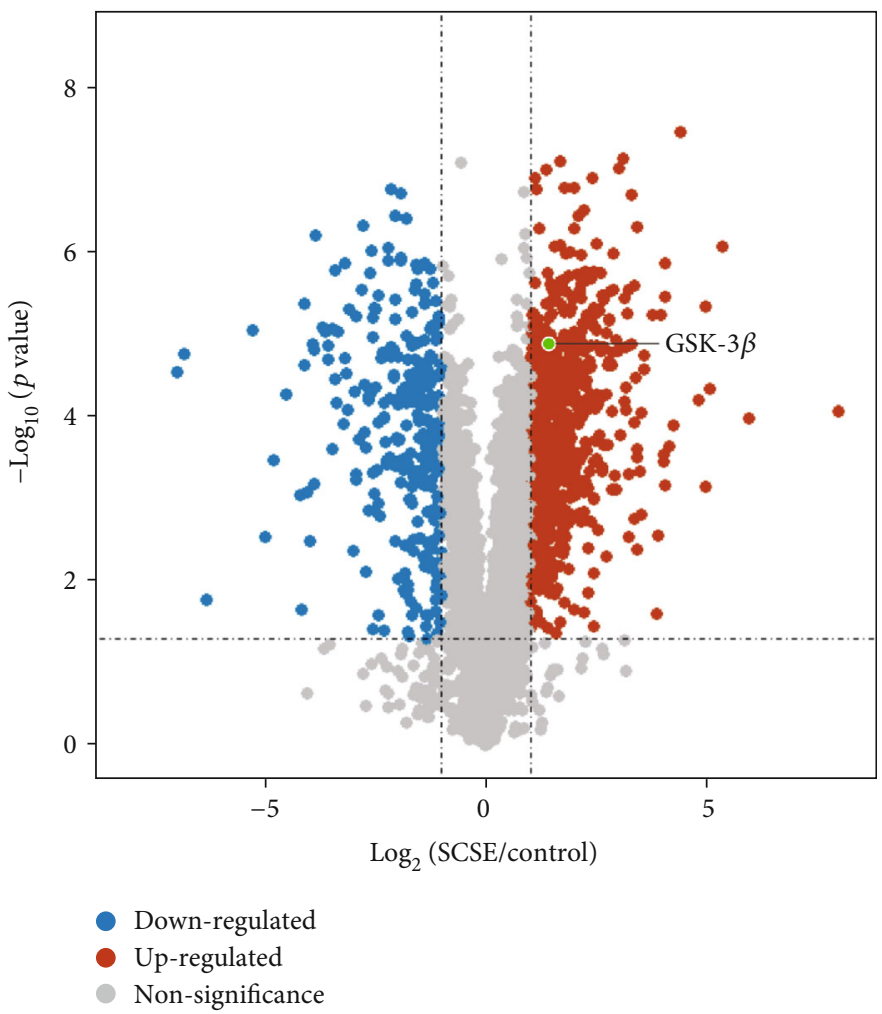

Figure 3: Volcano plot of the 1107 differentially expressed proteins in simulated complex space environment. A significant up- or downregulation at the protein level is characterized by SCSE/control ratio cutoff of \pm 2 with $p$ value $<0.05$. The upregulated proteins and downregulated proteins are shown in blue and red, respectively. The nonsignificant proteins are shown in gray.

of $\mathrm{A}$ is $98 \%$ water with $0.1 \%$ formic acid, and $\mathrm{B}$ is $98 \% \mathrm{ACN}$ with $0.1 \%$ formic acid. The whole gradient is $90 \mathrm{~min}$, containing 5\%-22\% B over $60 \mathrm{~min}, 22 \%-30 \% \mathrm{~B}$ for $10 \mathrm{~min}$, and $30 \%$ $80 \%$ for $5 \mathrm{~min}$, kept at $80 \%$ for $7 \mathrm{~min}$, and then held at $5 \%$ for another $8 \mathrm{~min}$. Each cycle of data-dependent acquisition included a $250 \mathrm{~ms}$ MS scan (350-1500 Da) and a $50 \mathrm{~ms}$ MS/MS scan (100-1500 Da) for ions with charge state from +2 to +5 , and the total number of MS/MS scans is 40 . Selected ions and their isotopes were dynamically excluded for $20 \mathrm{~s}$. Collision energy was set to optimum energy for ions with a $15 \mathrm{eV}$ collision energy spread. The mass spectrometer was always operated in high sensitivity mode.

2.7. LC-SWATH Analysis. The LC parameters of SWATH analysis is the same as those of the LC-ESI-DDA analysis. In the mass spectrometer, the $m / z$ range of $400-1250$ is automatically divided to 60 windows with different widths based on $\mathrm{m} / \mathrm{z}$ density. Precursor selection windows had an overlap of $1 \mathrm{Da}$ with each adjacent window to ensure full isotope coverage between SWATH blocks.

2.8. Database Searches and Statistics. DDA spectrum processing and database searching were performed with ProteinPilot (v5.0, AB Sciex) by using the Paragon algorithm. The search parameters are as follows: sample type: identification; cys alkylation: iodoacetamide; digestion: trypsin; instrument: TripleTOF 6600; special factors: none; and ID focus: biological modifications. The database was downloaded from UniProt (20150407), containing 29,389 sequences of Rattus norvegicus. The data was imported into Perseus (v.1.6.2.3) for statistics analysis. The expression values were logtransformed with base 2 and then used for heat map analysis and unpaired two-tailed Student's $t$-test. Differentially expressed proteins were identified with a significance threshold set at a $p$ value $<0.05$ and fold change of intensities calculated as SCSE/control ratio $>2$ or $<0.5$. DAVID 6.8 bioinformatics tools (https://david.ncifcrf.gov/) [44] were used for gene ontology (GO) functional annotation and Kyoto Encyclopedia of Genes and Genomes (KEGG) analysis of differentially expressed proteins.

2.9. Western Blot Analysis. Hippocampus membrane from control and SCSE rats were dissolved in RIPA lysis buffer. The supernatants were collected after centrifugation at $16,500 \times \mathrm{g}$ for $20 \mathrm{~min}$ at $4^{\circ} \mathrm{C}$. Protein concentrations were measured using the BCA protein assay kit (Thermo Scientific Pierce, USA). Proteins were separated using $8 \%$ SDS-PAGE gel and transferred by electroblotting onto a $0.22 \mu \mathrm{m}$ PVDF membrane (Bio-Rad, USA). After blocking in 5\% skim milk for $2 \mathrm{~h}$ at room temperature, the membrane was incubated with primary antibody raised against GSK-3 $\beta$ (Abcam, USA) or GAPDH (ZSGB-BIO, China) at $4^{\circ} \mathrm{C}$ overnight. The membrane was then washed three times with TBST buffer followed by the addition of the appropriate secondary antibodies labeled with HRP at room temperature for $2 \mathrm{~h}$. GAPDH was detected using anti-GAPDH antibody as an internal control. The membrane was further washed with 


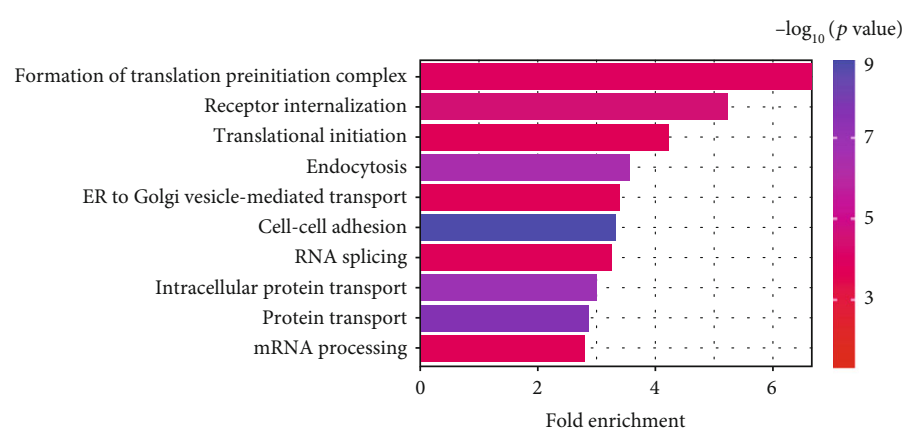

(a)

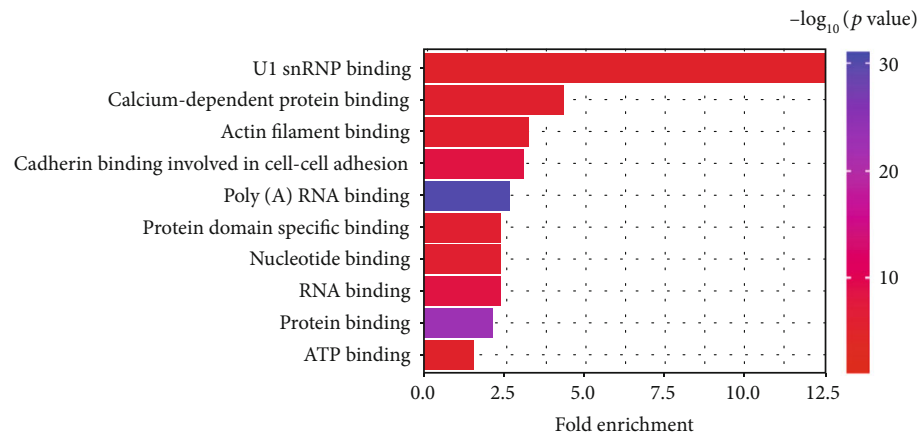

(b)

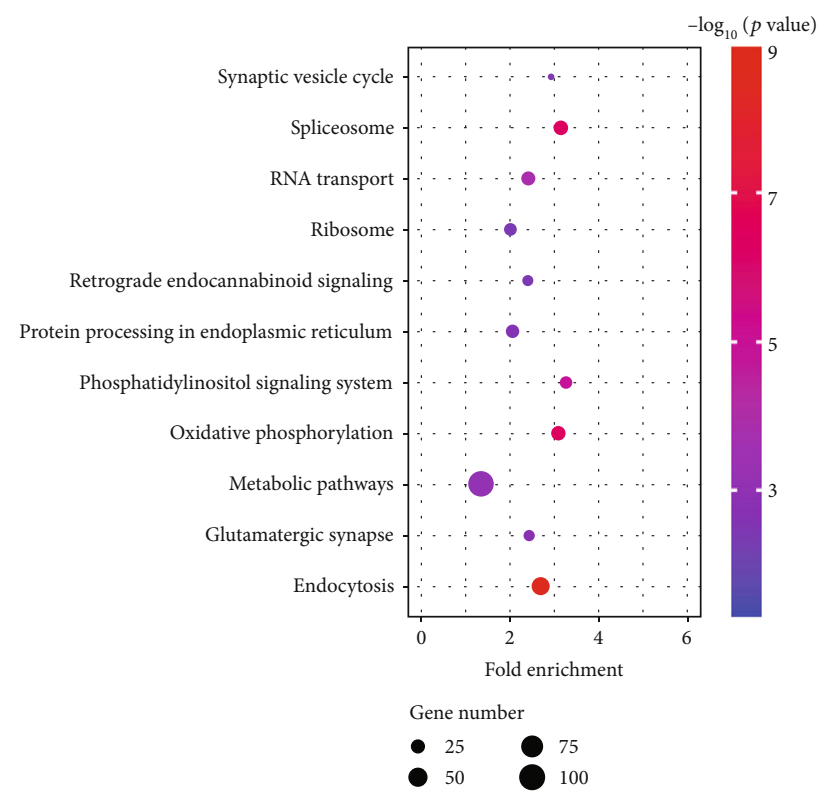

(c)

FIGURE 4: Functional enrichment of 1107 differential expressed proteins in simulated complex space environment: (a) GO biological process terms, (b) GO molecular function terms, and (c) KEGG pathways. The enriched pathways are shown with the $p$ value and gene number. The color represents the significance of enrichment.

TBST buffer three times and detected using ECL reagents (Millipore, USA).

\section{Results}

To test whether the SCSE rats exhibit the depression symptom, the sucrose preference and forced swimming and open-field tests were measured both in control and SCSE groups. Compared with the control group, the sucrose consumption level was significantly decreased in the SCSE group (Figure 1(a)). The reduction of partiality for sucrose is implemented as an indicator for appetite lack. The immobility time in SCSE rats increased remarkably by the forced swimming test (Figure 1(b)). The increase of the immobility time in FST is a sign of behavioral desperation. The open-field test was used to examine the motivation level of the SCSE rats. Compared with control rats, SCSE rats showed a significant decrease in crossings and rears of open-field activity, which indicated that SCSE rats had low interest in moving. And the same trend was shown in the central stop, whereas the grooming and fecal pellet were significantly elevated in the SCSE group (Figure 2). Taken together, these results indicated that the rats in the SCSE group exhibited the depression-like behavior.

We used SWATH to perform MS/MS-based label-free quantification. The results may demonstrate the high repro- ducibility of MS/MS-based quantification using SWATH of rat hippocampal membrane proteins. The samples were first analyzed using a DDA method to perform traditional database searching and build the hippocampal protein database. The analysis was performed using the same nLC gradient as the following SWATH analysis. The obtained spectral library was loaded into Peakview together with the SWATH runs to map the peptides in all the replicates. We identified and mapped 4520 proteins in all SWATH runs by merging the results of both the samples. A total of 810 proteins were upregulated while 297 proteins were downregulated in SCSE rats $(p<0.05)$, which was viewed visually in Figure 3.

The 1107 differentially expressed proteins were analyzed using DAVID to extract the GO annotation terms and KEGG clusters. As shown in Figures 4(a) and 4(b), the enrichment of GO biological process (BP) and GO molecular function (MF) was assessed in the hippocampus proteome under SCSE. GO-BP terms with the top 5 enrichment were formation of translation preinitiation complex, receptor internalization, translational initiation, endocytosis, and ER to Golgi vesicle-mediated transport. Enriched GO-MF terms with top 5 were U1snRNP binding, calcium-dependent protein binding, actin filament binding, cadherin binding involved in cell-cell adhesion, and poly(A) RNA binding. The enriched KEGG clusters involved in synaptic 
TABle 1: Differentially expressed proteins of endocytosis, glutamatergic synapse, and synaptic vesicle cycle.

\begin{tabular}{|c|c|c|c|c|}
\hline Pathway name & $\begin{array}{l}\text { Database } \\
\text { accession }\end{array}$ & Gene name & Protein name & $\begin{array}{c}\text { Fold change } \\
\text { (SCSE/control) }\end{array}$ \\
\hline \multirow{46}{*}{ Endocytosis } & B1WBS4 & Vps26b & $\begin{array}{l}\text { Similar to vacuolar protein sorting } 26 \text { homolog } \\
\text { (VPS26 protein homolog), isoform CRA_a }\end{array}$ & 5.16 \\
\hline & D3ZL11 & Rbsn & Rabenosyn, RAB effector & 2.66 \\
\hline & G3V8J5 & Psd & $\mathrm{PH}$ and SEC7 domain-containing protein 1 & 0.29 \\
\hline & $\mathrm{P} 18484$ & Ap2a2 & AP-2 complex subunit alpha-2 & 3.26 \\
\hline & F1LMX1 & Bin 1 & Myc box-dependent-interacting protein 1 & 2.05 \\
\hline & F1LUA1 & Eea1 & Early endosome antigen 1 & 0.25 \\
\hline & E9PSY8 & Eps15 & Epidermal growth factor receptor pathway substrate 15 & 2.26 \\
\hline & P26819 & Grk3 & Beta-adrenergic receptor kinase 2 & 7.09 \\
\hline & P62332 & Arf6 & ADP-ribosylation factor 6 & 2.38 \\
\hline & P08081 & Clta & Clathrin light chain A & 0.35 \\
\hline & B2RZ72 & Arpc4 & Actin-related protein $2 / 3$ complex subunit 4 & 3.86 \\
\hline & D3ZXP7 & Arpcla & Actin-related protein $2 / 3$ complex subunit $1 \mathrm{~A}$ & 2.67 \\
\hline & P26817 & Grk2 & Beta-adrenergic receptor kinase 1 & 4.27 \\
\hline & Q66HM2 & Ap2a2 & AP-2 complex subunit alpha & 3.24 \\
\hline & F1LQP0 & Cyth3 & Cytohesin-3 & 2.91 \\
\hline & Q99PD4 & Arpcla & Actin-related protein $2 / 3$ complex subunit $1 \mathrm{~A}$ & 3.07 \\
\hline & B5DEY8 & Snx6 & Sorting nexin & 2.33 \\
\hline & A0A0A0MY49 & Dnm2 & Dynamin GTPase & 0.45 \\
\hline & G3V8A5 & Vps35 & Vacuolar protein sorting-associated protein 35 & 2.53 \\
\hline & B2RYP4 & Snx2 & Sorting nexin-2 & 2.18 \\
\hline & B2RZ78 & Vps29 & Vacuolar protein sorting-associated protein 29 & 5.12 \\
\hline & D3ZD48 & Rab11fip2 & $\begin{array}{l}\text { RAB11 family interacting protein } 2 \\
\text { (class I) (predicted), isoform CRA_a }\end{array}$ & 2.27 \\
\hline & B1WBX6 & Smap2 & Small ArfGAP2 & 4.65 \\
\hline & F1M8B7 & Chmp2b & Charged multivesicular body protein $2 \mathrm{~B}$ & 0.48 \\
\hline & P29067 & Arrb2 & Beta-arrestin-2 & 7.41 \\
\hline & G3V8M6 & Folr1 & Folate receptor 1 (adult), isoform CRA_b & 0.42 \\
\hline & O08839 & Bin1 & Myc box-dependent-interacting protein 1 & 2.91 \\
\hline & Q6AY86 & Vps26a & Vacuolar protein sorting-associated protein $26 \mathrm{~A}$ & 8.65 \\
\hline & B2RZB5 & Chmp2a & Charged multivesicular body protein $2 \mathrm{~A}$ & 2.65 \\
\hline & $\mathrm{B} 1 \mathrm{H} 248$ & Vps36 & Vacuolar protein-sorting-associated protein 36 & 3.82 \\
\hline & Q8R491 & Ehd3 & EH domain-containing protein 3 & 3.10 \\
\hline & Q99N27 & Snx1 & Sorting nexin-1 & 2.74 \\
\hline & G3V9U1 & Agap1 & ArfGAP with GTPase domain, ankyrin repeat and PH domain 1 & 3.15 \\
\hline & D3ZSI8 & Pip5k1a & Phosphatidylinositol 4-phosphate 5-kinase type-1 alpha & 2.64 \\
\hline & Q8R3Z7 & Ehd 4 & EH-domain-containing 4 & 6.05 \\
\hline & F1LMA4 & Grk2 & G protein-coupled receptor kinase & 4.98 \\
\hline & Q4KLL7 & Vps4b & Vesicle-fusing ATPase & 5.29 \\
\hline & M0RC57 & Smap1 & Small ArfGAP 1 & 3.33 \\
\hline & B2GV73 & Arpc3 & Actin-related protein $2 / 3$ complex subunit 3 & 5.92 \\
\hline & B2GUV0 & Cyth1 & Cyth1 protein & 3.27 \\
\hline & F1LSU6 & Cyth2 & Cytohesin-2 & 0.07 \\
\hline & P0C0A1 & Vps25 & Vacuolar protein-sorting-associated protein 25 & 2.57 \\
\hline & B2GUZ5 & Capzal & F-actin-capping protein subunit alpha-1 & 3.49 \\
\hline & D3ZKX1 & Washc3 & Coiled-coil domain-containing protein 53 & 2.81 \\
\hline & D3ZJR1 & Eps15l1 & Epidermal growth factor receptor pathway substrate 15 -like 1 & 2.66 \\
\hline & Q9Z1Z3 & Epn2 & Epsin-2 & 3.10 \\
\hline
\end{tabular}


TABLe 1: Continued.

\begin{tabular}{|c|c|c|c|c|}
\hline Pathway name & $\begin{array}{l}\text { Database } \\
\text { accession }\end{array}$ & Gene name & Protein name & $\begin{array}{l}\text { Fold change } \\
\text { (SCSE/control) }\end{array}$ \\
\hline & P21575 & Dnm1 & Dynamin-1 & 3.99 \\
\hline & B5DF55 & Stam & RCG55706 & 2.26 \\
\hline \multirow{17}{*}{$\begin{array}{l}\text { Glutamatergic } \\
\text { synapse }\end{array}$} & P19492 & Gria3 & Glutamate receptor 3 & 2.73 \\
\hline & P10824 & Gnail & Guanine nucleotide-binding protein G(i) subunit alpha-1 & 0.32 \\
\hline & Q63273 & Grik5 & Glutamate receptor ionotropic, kainate 5 & 0.30 \\
\hline & D4A3N4 & Adcy1 & Adenylate cyclase type 1 & 2.31 \\
\hline & G3V846 & Slc1a3 & Amino acid transporter & 4.14 \\
\hline & P43425 & Gng7 & $\begin{array}{l}\text { Guanine nucleotide-binding protein } \\
\mathrm{G}(\mathrm{I}) / \mathrm{G}(\mathrm{S}) / \mathrm{G}(\mathrm{O}) \text { subunit gamma-7 }\end{array}$ & 4.63 \\
\hline & P63100 & Ppp3r1 & Calcineurin subunit B type 1 & 3.14 \\
\hline & P26819 & Grk3 & Beta-adrenergic receptor kinase 2 & 7.09 \\
\hline & D4AE68 & Gnaq & $\begin{array}{l}\text { Guanine nucleotide binding protein, } \\
\text { alpha q polypeptide, isoform CRA_a }\end{array}$ & 2.74 \\
\hline & G3V6R0 & Slc1a2 & Amino acid transporter & 0.17 \\
\hline & MORBJ0 & Gng2 & Guanine nucleotide-binding protein subunit gamma & 2.13 \\
\hline & P26817 & Grk2 & Beta-adrenergic receptor kinase 1 & 4.27 \\
\hline & Q9Z2X5 & Homer3 & Homer protein homolog 3 & 0.35 \\
\hline & F1LS42 & Prkcb & Protein kinase $\mathrm{C}$ & 0.44 \\
\hline & Q9JHZ9 & Slc38a3 & Sodium-coupled neutral amino acid transporter 3 & 2.44 \\
\hline & Q3KRE3 & Gng10 & Guanine nucleotide-binding protein subunit gamma & 3.24 \\
\hline & M0R809 & Gng4 & Guanine nucleotide-binding protein subunit gamma & 3.24 \\
\hline \multirow{11}{*}{ Synaptic vesicle cycle } & P08081 & Clta & Clathrin light chain A & 0.35 \\
\hline & P63041 & Cplx1 & Complexin-1 & 39.73 \\
\hline & P62815 & Atp6v1b2 & V-type proton ATPase subunit B, brain isoform & 3.13 \\
\hline & Q5FVI6 & Atp6v1c1 & V-type proton ATPase subunit C 1 & 2.66 \\
\hline & P18484 & Ap2a2 & AP-2 complex subunit alpha & 3.26 \\
\hline & P63081 & Atp6v0c & V-type proton ATPase $16 \mathrm{kDa}$ proteolipid subunit & 2.03 \\
\hline & A0A0A0MY49 & Dnm2 & Dynamin GTPase & 0.45 \\
\hline & P32851 & Stxla & Syntaxin-1A & 0.37 \\
\hline & Q8R2H0 & Atp6v1g2 & V-type proton ATPase subunit G & 3.25 \\
\hline & B2GUV5 & Atp6v1g1 & V-type proton ATPase subunit G & 2.07 \\
\hline & P21575 & Dnm1 & Dynamin-1 & 3.99 \\
\hline
\end{tabular}

transmission, such as endocytosis ( $p$ value, 3.44e-09), glutamatergic synapse ( $p$ value, $1.47 \mathrm{e}-03$ ), and synaptic vesicle cycle ( $p$ value, 3.81e-03), are shown in Figure 4(c). The proteins associated with these three pathways are listed in Table 1 and shown as the heat map in Figure 5. It is well known that proteins interact with each other and perform the function together.

To validate mass spectrometry results, western blot was used to analyze the upregulated protein GSK-3 $\beta$ with GAPDH as internal standard. As shown in Figure 6, the abundance of GSK-3 $\beta$ significantly increased in the SCSE model, which was consistent with the mass spectrometry results.

GSK- $3 \beta$ is a protein hub linking numerous signaling pathways in a cell. The activity of GSK $3 \beta$ affects energy metabolism, cell survival, proliferation, apoptosis, membrane polarity, internalization of the synaptic receptors, neuroplasticity, neurotransmission, amyloid processing, and many other processes. A previous study showed that specific GSK $3 \beta$ inhibitors have antidepressant effects and decrease depressive-like behavior in animal models of depression. Therefore, GSK $3 \beta$ is suggested to be engaged in the pathogenesis of major depressive disorder and to be a target and/or modifier of antidepressants' action. The increase on GSK3 $\beta$ activity has also been found in platelets of depressed patients. So GSK3 $\beta$ was selected for the western blotting verification.

\section{Discussion}

The present study is unique and of utmost importance regarding step towards safe space travelling as well as 
SCSE
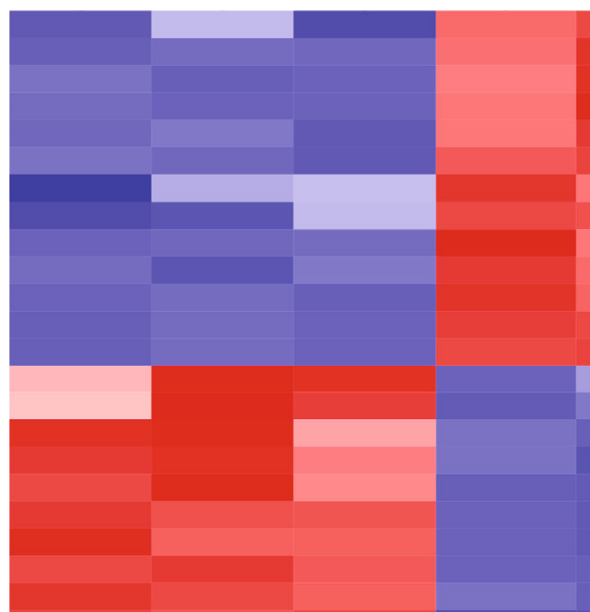

Control
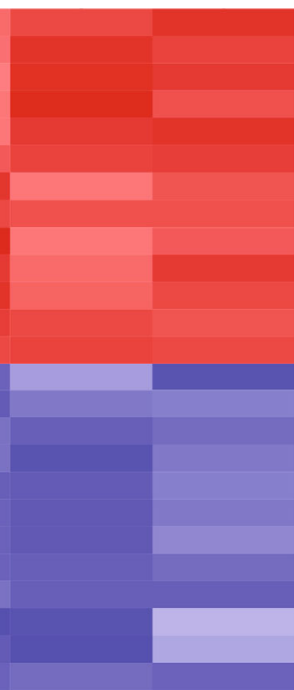

\section{Grik5}

Eeal

Prkcb

Folr 1

Homer3

Dnm2

Chmp2b

Cyth2

txla

Gnail

Clta

Slcla2

tam

Adcy1

Pip5k1a

Pip5kla

Atp6v0

Grk3

Snx

Epn2

nnx6

Gng2

Rosn

Ehd3

Atp6v1g1

Arf6

Cplx1

Atp6v1b2

Vps26a

Smap2

Vps35

Gng7

Atp6v1g2

Smap1

Slc38a3

Arpcla

Atp6v1c1

Vps29

Grk2

Vps26b

SIcla3

Dnm1

Arpc4

Ap2a2

Washc3

Arpc3

Rab11fip2

Gnaq

Agap1

Snx2

Gng10

Vps25

Gria3

Ehd4

Vps4b

Capzal

Bin 1

Cyth1

Ppp3r1

Arrb2

Eps15

Tps36

Vps36

Chmp2a
0.5

$Z$-score

1

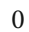

$-0.5$

$-1$

FIGURE 5: The heat map depicting the Z-score of the abundance of differentially expressed proteins related to endocytosis, glutamatergic synapse and synaptic vesicle cycle between the control group and SCSE group.

establishment of space stations for future research purposes. It helps to uncover the mechanisms of biological effects of extreme environmental conditions. Astronauts face disturbance in their mental and physical health during prolonged stay in space. This compels them to limit their stay in space affecting not only their health but also their capability to conduct experiments in space. The present study is an effort to establish a proteomic approach to find the key proteins involved in cognitive imbalances and to develop the future preventive strategies.

A previous study showed that simulated weightlessness may cause depression, anxiety, and nervous symptom occurred by emotional behavior test. However, the action mechanism of these side effects is unclear.

Our results showed the SCSE rat depression symptoms by the sucrose consumption, the open-field, and forced 

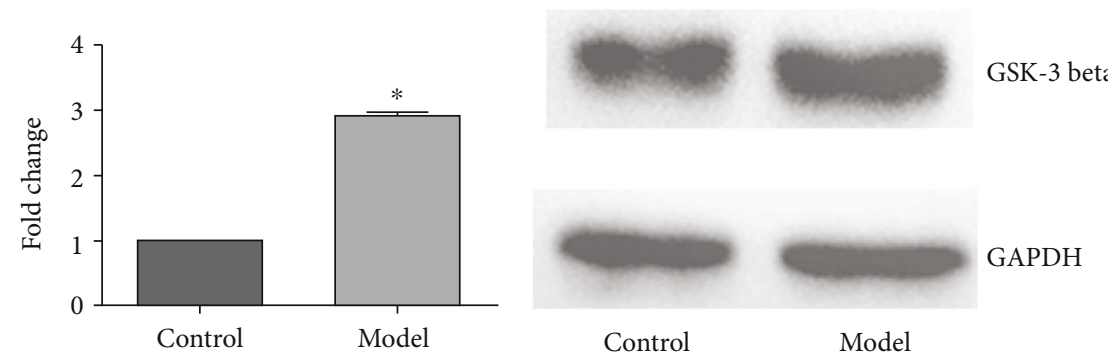

FIGURE 6: Quantification of upregulated protein GSK-3 $\beta$ with GAPDH as internal standard. The results show that the GSK-3 $\beta$ level determined by western blotting analysis was consistent with mass spectrometry. Data are expressed as mean \pm SD, and $p$ value was determined by an unpaired Student $t$-test. ${ }^{*} p<0.05$, vs. the control group.

swimming tests. Here, we employed SWATH label-free quantitative proteomics approach to quantify the expression of hundreds of membrane proteins in the hippocampus in response to depression symptom. Out of 4520 quantified proteins, 244 differentially expressed membrane proteins were obtained between the SCSE and control rats, which were functionally enriched in a series of biological processes, such as translation, protein phosphorylation, brain development, endocytosis, nervous system development, axonogenesis, and vesicle-mediated transport. These biological processes may affect the cognition and emotion; large proportions of protein alterations were found involved in cognitive dysfunction, bad mood states, and risky decision making.

Among the enriched pathways, endocytosis, RNA transport, ribosome, phosphatidylinositol signaling system, glutamatergic synapse, protein processing in endoplasmic reticulum and dopaminergic synapse, and so on are significantly activated.

We found different levels of light neurofilament subunit (NF-L), Ubiquitin C-terminal hydrolase-L1 (UCHL1), calreticulin, synaptojanin-1, Munc18-1, synaptotagmin, AP180, the plasma membrane $\mathrm{Ca}^{2+}$-ATPase (PMCA), snapin, neurexin-2, neuroligin-1, rab 18 , synaptogyrin 1 , syntaxin-1A, and complexin-1, which were associated with nervous system development, axonogenesis, vesicle-mediated transport, etc. All the proteins were involved in depression and account for depression induced by the complex space environment.

It is reported that depression is associated with hippocampal protein changes. NFL decreased in both CA3 and dentate gyrus in the depressed model. A similar trend is found in our results. It is located in the core of mature neurofilament, which is downregulated indicating that neurofilament assembly was disturbed in the hippocampal depression-associated rat model $[44,45]$. UCHL1 as a neuron-specific deubiquitinase is a potential biomarker of cerebrospinal fluid (CSF) for neuronal loss. The result showed that this protein was downregulated suggesting a failure of axonal transport in SCSE rats [46-48]. Calreticulin is a lectin chaperone of the endoplasmic reticulum (ER) [46-48]. Activation of calreticulin may contribute to mood stability in the rat brain. It was downregulated in our model indicating a mood instability $[49,50]$.

Synaptojanin-1 is a polyphosphoinositide inositol phosphatase that is concentrated in presynaptic nerve endings, where it is dephosphorylated by calcineurin. Moreover, it also participated in clathrin-mediated endocytosis and astrogliogenesis of neural precursor cells [51-53]. Its downregulation indicates that clathrin-mediated endocytosis may be affected.

Munc18-1 is essential for soluble N-ethylmaleimidesensitive factor attachment protein receptor- (SNARE-) mediated membrane fusion/exocytosis via binding to SNARE complex. Moreover, it is key regulatory protein in synaptic transmission and controls every step in the exocytotic pathway in the central nervous system [54-57]. Munc18 is upregulated in the SCSE rat model as compared to control. The disruption of munc18 binding to syntaxin-1 had a significant effect on the behavior of secretory vesicles and the possibility fusion [58]. Synaptotagmin (Syt) functions as a $\mathrm{Ca}^{2+}$ sensor on the membrane of secretory vesicles of neurons [59-61]. Clathrin coat assembly protein (SNAP91 or AP180) is a key protein in synaptic vesicle recycling $[51,52]$ and may be related to psychiatric disorders $[53,54,60]$. It plays a key role in establishing the polarity and controlling the growth of axons and dendrites in embryonic hippocampal neurons [62]. Overexpressed AP180 generating multiple axons is a compensation adaption during stressed conditions [62].

CaMKII-delta is required for the CaMKII-dependent regulation of ASK1, affecting the apoptosis of a biologically important cell type under spinal cord injury. Activation of CaMKII reduces the deactivation of the voltage-gate outward $\mathrm{K}^{+}$current $[63,64]$. The PMCA is a calcium pump specially used for neurons, where it may regulate the $\mathrm{Ca}^{2+}$ transients in somatic and dendritic cells [65].

The upregulation of snapin may cause the reduction of the number of primary dendrites and increase the branches in primary culture hippocampal neurons. However, it has no effect on the release of a neurotransmitter $[66,67]$. EHD1 may cause the inhibition of exocytosis by affecting the binding of the SNARE complex, SNAP-25, and snapin and coupling of synaptotagmin-1 $[68,69]$.

The nervous system development may be disturbed under the SCSE, mainly displaying in the formation of synapse and neuron regeneration. The downregulation of neurexin-2 (NRX2), the light, medium, heavy polypeptide of neurofilament, and upregulation of neuroligin-1 all indicated the abnormal development of axon and neurons. Moreover, some downregulated proteins were found involved in synaptic transmission including rab 18 , 
synaptogyrin 1, and syntaxin-1A. On the other hand, munc18, snapin, synaptotagmin XII, and complexin-1 were upregulated. All the proteins may play a key part in the development of depression. These differentially expressed proteins will be used as biomarkers for future space research and might provide some helpful clues for formulating strategies to improve or maintain the mental and physical health of astronauts during space travel.

\section{Data Availability}

The raw data required to reproduce these findings cannot be shared at this time as the data also forms part of an ongoing study.

\section{Conflicts of Interest}

We declare that we have no financial and personal relationships with other people or organizations that can inappropriately influence our work.

\section{Acknowledgments}

This work was supported by the Youth Program of National Natural Science Foundation of China (Grant No. 81801073).

\section{Supplementary Materials}

Differentially expressed proteins between the control group and SCSE group. (Supplementary Materials)

\section{References}

[1] Y. Ishizaki, T. Ishizaki, H. Fukuoka et al., "Changes in mood status and neurotic levels during a 20-day bed rest," Acta Astronautica, vol. 50, no. 7, pp. 453-459, 2002.

[2] X. Liang, L. Zhang, Y. Wan et al., "Changes in the diurnal rhythms during a 45-day head-down bed rest," PLoS One, vol. 7, no. 10, article e47984, 2012.

[3] N. A. M. Stavrou, A. C. McDonnell, O. Eiken, and I. B. Mekjavic, "Psychological strain: examining the effect of hypoxic bedrest and confinement," Physiology \& Behavior, vol. 139, pp. 497-504, 2015.

[4] G. Bu, F. Shuang, Y. Wu, D. Ren, and S. Hou, "AQP9: a novel target for bone loss induced by microgravity," Biochemical and Biophysical Research Communications, vol. 419, no. 4, pp. 774-778, 2012.

[5] N. Shiba, H. Matsuse, Y. Takano et al., "Electrically stimulated antagonist muscle contraction increased muscle mass and bone mineral density of one astronaut - initial verification on the International Space Station," PLoS One, vol. 10, no. 8, article e0134736, 2015.

[6] D. Grimm, J. Grosse, M. Wehland et al., "The impact of microgravity on bone in humans," Bone, vol. 87, pp. 44-56, 2016.

[7] Z. Wang, Y. Bai, J. Yu et al., "Caveolae regulate vasoconstriction of conduit arteries to angiotensin II in hindlimb unweighted rats," The Journal of Physiology, vol. 593, no. 20, pp. 4561-4574, 2015.

[8] J. L. Morel, F. Dabertrand, Y. Porte, A. Prevot, and N. Macrez, "Up-regulation of ryanodine receptor expression increases the calcium-induced calcium release and spontaneous calcium sig- nals in cerebral arteries from hindlimb unloaded rats," Pflugers Archiv : European journal of physiology, vol. 466, no. 8, pp. 1517-1528, 2014.

[9] B. Gerber, J. L. Singh, Y. Zhang, and W. Liou, "A computer simulation of short-term adaptations of cardiovascular hemodynamics in microgravity," Computers in Biology and Medicine, vol. 102, pp. 86-94, 2018.

[10] F. Gaignier, V. Schenten, M. De Carvalho Bittencourt, G. Gauquelin-Koch, J. P. Frippiat, and C. Legrand-Frossi, "Three weeks of murine hindlimb unloading induces shifts from $\mathrm{B}$ to $\mathrm{T}$ and from $\mathrm{Th}$ to $\mathrm{Tc}$ splenic lymphocytes in absence of stress and differentially reduces cell-specific mitogenic responses," PLoS One, vol. 9, no. 3, article e92664, 2014.

[11] A. Risso, G. Tell, C. Vascotto et al., "Activation of human T lymphocytes under conditions similar to those that occur during exposure to microgravity: a proteomics study," Proteomics, vol. 5, no. 7, pp. 1827-1837, 2005.

[12] H. Aviles, T. Belay, M. Vance, and G. Sonnenfeld, "Effects of space flight conditions on the function of the immune system and catecholamine production simulated in a rodent model of hindlimb unloading," Neuroimmunomodulation, vol. 12, no. 3 , pp. 173-181, 2005.

[13] S. Iwase and T. Mano, "[Microgravity and autonomic nervous system], Nihon rinsho," Japanese journal of clinical medicine, vol. 58, no. 8, pp. 1604-1612, 2000.

[14] K. Li, X. Guo, Z. Jin et al., "Effect of simulated microgravity on human brain gray matter and white matter - evidence from MRI," PLoS One, vol. 10, no. 8, article e0135835, 2015.

[15] A. Ranjan, J. Behari, and B. N. Mallick, "Cytomorphometric changes in hippocampal CA1 neurons exposed to simulated microgravity using rats as model," Frontiers in Neurology, vol. 5, 2014.

[16] R. Jandial, R. Hoshide, J. D. Waters, and C. L. Limoli, "Spacebrain: the negative effects of space exposure on the central nervous system," Surgical Neurology International, vol. 9, no. 1, p. 9, 2018.

[17] S. F. Jiang and Y. F. Gao, "Effects of simulated weightlessness on emotional behaviour in rats," Chinese Journal of Applied Physiology, vol. 28, no. 3, pp. 205-208, 2012.

[18] D. J. Newman and C. E. Lathan, "Memory processes and motor control in extreme environments," IEEE Transactions on Systems, Man and Cybernetics, Part C (Applications and Reviews), vol. 29, no. 3, pp. 387-394, 1999.

[19] L. L. Rao, Y. Zhou, Z. Y. Liang et al., "Decreasing ventromedial prefrontal cortex deactivation in risky decision making after simulated microgravity: effects of $-6^{\circ}$ head-down tilt bed rest," Frontiers in Behavioral Neuroscience, vol. 8, p. 187, 2014.

[20] Y. Zhou, Y. Wang, L. L. Rao et al., "Disrutpted resting-state functional architecture of the brain after 45-day simulated microgravity," Frontiers in Behavioral Neuroscience, vol. 8, p. 200, 2014.

[21] X. Zhang, X. Chu, L. Chen et al., "Simulated weightlessness procedure, head-down bed rest impairs adult neurogenesis in the hippocampus of rhesus macaque," Molecular Brain, vol. 12, no. 1, p. 46, 2019.

[22] J. Wang, C. Liu, T. Li, Y. Wang, and D. Wang, "Proteomic analysis of pulmonary tissue in tail-suspended rats under simulated weightlessness," Journal of Proteomics, vol. 75, no. 17, pp. 5244-5253, 2012.

[23] J. Iqbal, W. Li, M. Hasan et al., "Distortion of homeostatic signaling proteins by simulated microgravity in rat 
hypothalamus: A(16) O/(18) O-labeled comparative integrated proteomic approach," Proteomics, vol. 14, no. 2-3, pp. 262-273, 2014.

[24] J. Iqbal, W. Li, M. Hasan et al., "Differential expression of specific cellular defense proteins in rat hypothalamus under simulated microgravity induced conditions: comparative proteomics," Proteomics, vol. 14, no. 11, pp. 1424-1433, 2014.

[25] K. C. Wise, S. K. Manna, K. Yamauchi et al., "Activation of nuclear transcription FACTOR $-\kappa \mathrm{B}$ in mouse brain induced by a simulated microgravity environment," In Vitro Cellular \& Developmental Biology - Animal, vol. 41, no. 3, pp. 118123, 2005.

[26] P. Sarkar, S. Sarkar, V. Ramesh et al., "Proteomic analysis of mice hippocampus in simulated microgravity environment," Journal of Proteome Research, vol. 5, no. 3, pp. 548-553, 2006.

[27] P. Sarkar, S. Sarkar, V. Ramesh et al., "Proteomic analysis of mouse hypothalamus under simulated microgravity," Neurochemical Research, vol. 33, no. 11, pp. 2335-2341, 2008.

[28] S. Sarkar, K. C. Wise, S. K. Manna et al., "Activation of activator protein-1 in mouse brain regions exposed to simulated microgravity," In Vitro Cellular \& Developmental Biology. Animal, vol. 42, no. 3, pp. 96-99, 2006.

[29] E. R. Morey-Holton and R. K. Globus, "Hindlimb unloading rodent model: technical aspects," Journal of Applied Physiology (Bethesda, Md. : 1985), vol. 92, no. 4, pp. 1367-1377, 2002.

[30] G. Hu, Y. Ma, Y. Zhou, D. Cai, S. Xiao, and Y. Deng, "SNAREs-related pathways in rat brains under simulated microgravity environment," in 2009 3rd International Conference on Bioinformatics and Biomedical Engineering, pp. 19-25, Beijing, China, June 2009.

[31] Y. Wang, J. Iqbal, Y. Liu et al., "Effects of simulated microgravity on the expression of presynaptic proteins distorting the GABA/glutamate equilibrium - a proteomics approach," Proteomics, vol. 15, no. 22, pp. 3883-3891, 2015.

[32] Y. Wang, I. Javed, Y. Liu et al., "Effect of prolonged simulated microgravity on metabolic proteins in rat hippocampus: steps toward safe space travel," Journal of Proteome Research, vol. 15, no. 1, pp. 29-37, 2016.

[33] Q. Huang, L. Yang, J. Luo et al., "SWATH enables precise label-free quantification on proteome scale," Proteomics, vol. 15, no. 7, pp. 1215-1223, 2015.

[34] P. McQueen, V. Spicer, J. Schellenberg et al., "Whole cell, label free protein quantitation with data independent acquisition: quantitation at the MS2 level," Proteomics, vol. 15, no. 1, pp. 16-24, 2015.

[35] G. Hou, X. Lou, Y. Sun et al., "Biomarker discovery and verification of esophageal squamous cell carcinoma using integration of SWATH/MRM," Journal of Proteome Research, vol. 14, no. 9, pp. 3793-3803, 2015.

[36] K. Felix, K. Wise, S. Manna et al., "Altered cytokine expression in tissues of mice subjected to simulated microgravity," Molecular and Cellular Biochemistry, vol. 266, no. 1/2, pp. 79-85, 2004.

[37] L. Wei, Y. Diao, J. Qi et al., "Effect of change in spindle structure on proliferation inhibition of osteosarcoma cells and osteoblast under simulated microgravity during incubation in rotating bioreactor," PLoS One, vol. 8, no. 10, article e76710, 2013.
[38] K. T. Chen, C. H. Wu, M. H. Tsai et al., "Antidepressant-like effects of long-term sarcosine treatment in rats with or without chronic unpredictable stress," Behavioural Brain Research, vol. 316, pp. 1-10, 2017.

[39] K. Socała, D. Nieoczym, M. Pieróg, A. Szuster-Ciesielska, E. Wyska, and P. Wlaź, "Antidepressant-like activity of sildenafil following acute and subchronic treatment in the forced swim test in mice: effects of restraint stress and monoamine depletion," Metabolic Brain Disease, vol. 31, no. 5, pp. 10951104, 2016.

[40] J. Shen, J. Zhang, M. Deng, Y. Liu, Y. Hu, and L. Zhang, “The antidepressant effect of Angelica sinensis extracts on chronic unpredictable mild stress-induced depression is mediated via the upregulation of the BDNF signaling pathway in rats," Evidence-based Complementary and Alternative Medicine, vol. 2016, Article ID 7434692, 8 pages, 2016.

[41] X. Zhang, Q. Wang, Y. Wang et al., "Duloxetine prevents the effects of prenatal stress on depressive-like and anxiety-like behavior and hippocampal expression of proinflammatory cytokines in adult male offspring rats," International Journal of Developmental Neuroscience, vol. 13, no. 16, p. 005, 2016.

[42] B. Cox and A. Emili, "Tissue subcellular fractionation and protein extraction for use in mass- spectrometry-based proteomics," Nature Protocols, vol. 1, no. 4, pp. 1872-1878, 2006.

[43] H. Heide, L. Bleier, M. Steger et al., "Complexome profiling identifies TMEM126B as a component of the mitochondrial complex I assembly complex," Cell Metabolism, vol. 16, no. 4, pp. 538-549, 2012.

[44] A. J. Ferrero, M. Cereseto, L. L. Sifonios et al., "Cytoskeleton of hippocampal neurons as a target for valproic acid in an experimental model of depression," Progress in Neuro-Psychopharmacology \& Biological Psychiatry, vol. 31, no. 7, pp. 1419-1428, 2007.

[45] A. Reines, M. Cereseto, A. Ferrero, C. Bonavita, and S. Wikinski, "Neuronal cytoskeletal alterations in an experimental model of depression," Neuroscience, vol. 129, no. 3, pp. 529-538, 2004.

[46] K. Bilguvar, N. K. Tyagi, C. Ozkara et al., "Recessive loss of function of the neuronal ubiquitin hydrolase UCHL1 leads to early-onset progressive neurodegeneration," Proceedings of the National Academy of Sciences of the United States of America, vol. 110, no. 9, pp. 3489-3494, 2013.

[47] S. B. Lewis, R. Wolper, Y. Y. Chi et al., "Identification and preliminary characterization of ubiquitin $\mathrm{C}$ terminal hydrolase 1 (UCHL1) as a biomarker of neuronal loss in aneurysmal subarachnoid hemorrhage," Journal of Neuroscience Research, vol. 88, no. 7, pp. 1475-1484, 2010.

[48] I. N. M. Day and R. J. Thompson, "UCHL1 (PGP 9.5): neuronal biomarker and ubiquitin system protein," Progress in Neurobiology, vol. 90, no. 3, pp. 327-362, 2010.

[49] L. Shao, X. Sun, L. Xu, L. T. Young, and J. F. Wang, "Mood stabilizing drug lithium increases expression of endoplasmic reticulum stress proteins in primary cultured rat cerebral cortical cells," Life Sciences, vol. 78, no. 12, pp. 1317-1323, 2006.

[50] C. Howe, M. Garstka, M. Al-Balushi et al., "Calreticulindependent recycling in the early secretory pathway mediates optimal peptide loading of MHC class I molecules," The EMBO Journal, vol. 28, no. 23, pp. 3730-3744, 2009.

[51] F. Herrera, Q. Chen, W. H. Fischer, P. Maher, and D. R. Schubert, "Synaptojanin-1 plays a key role in astrogliogenesis: 
possible relevance for Down's syndrome," Cell Death and Differentiation, vol. 16, no. 6, pp. 910-920, 2009.

[52] F. Irie, M. Okuno, E. B. Pasquale, and Y. Yamaguchi, "EphrinB-EphB signalling regulates clathrin-mediated endocytosis through tyrosine phosphorylation of synaptojanin 1," Nature Cell Biology, vol. 7, no. 5, pp. 501-509, 2005.

[53] S. Y. Lee, M. R. Wenk, Y. Kim, A. C. Nairn, and P. De Camilli, "Regulation of synaptojanin 1 by cyclin-dependent kinase 5 at synapses," Proceedings of the National Academy of Sciences of the United States of America, vol. 101, no. 2, pp. 546-551, 2004.

[54] G. A. Han, N. R. Bin, S. Y. A. Kang, L. Han, and S. Sugita, "Domain 3a of Munc18-1 plays a crucial role at the priming stage of exocytosis," Journal of Cell Science, vol. 126, no. 11, pp. 2361-2371, 2013.

[55] D. Parisotto, M. Pfau, A. Scheutzow et al., "An extended helical conformation in domain 3a of Munc18-1 provides a template for SNARE (soluble N-ethylmaleimide-sensitive factor attachment protein receptor) complex assembly," The Journal of Biological Chemistry, vol. 289, no. 14, pp. 9639-9650, 2014.

[56] A. M. Smyth, L. Yang, K. J. Martin et al., "Munc18-1 protein molecules move between membrane molecular depots distinct from vesicle docking sites," The Journal of Biological Chemistry, vol. 288, no. 7, pp. 5102-5113, 2013.

[57] D. Bar-On, E. Nachliel, M. Gutman, and U. Ashery, "Dynamic conformational changes in munc18 prevent syntaxin binding," PLoS Computational Biology, vol. 7, no. 3, article e1001097, 2011.

[58] A. M. Smyth, C. Rickman, and R. R. Duncan, "Vesicle fusion probability is determined by the specific interactions of munc18," The Journal of Biological Chemistry, vol. 285, no. 49 , pp. 38141-38148, 2010.

[59] C. Saegusa, M. Fukuda, and K. Mikoshiba, "Synaptotagmin $\mathrm{V}$ is targeted to dense-core vesicles that undergo calciumdependent exocytosis in PC12 cells," The Journal of Biological Chemistry, vol. 277, no. 27, pp. 24499-24505, 2002.

[60] M. Craxton and M. Goedert, "Synaptotagmin V: a novel synaptotagmin isoform expressed in rat brain," FEBS Letters, vol. 361, no. 2-3, pp. 196-200, 1995.

[61] M. Iezzi, G. Kouri, M. Fukuda, and C. B. Wollheim, "Synaptotagmin $\mathrm{V}$ and IX isoforms control $\mathrm{Ca} 2+$-dependent insulin exocytosis," Journal of Cell Science, vol. 117, no. 15, pp. 3119-3127, 2004.

[62] I. Bushlin, R. S. Petralia, F. Wu et al., "Clathrin assembly protein AP180 and CALM differentially control axogenesis and dendrite outgrowth in embryonic hippocampal neurons," The Journal of Neuroscience, vol. 28, no. 41, pp. 1025710271, 2008.

[63] G. Liu, J. Zhao, Z. Chang, and G. Guo, "CaMKII activates ASK1 to induce apoptosis of spinal astrocytes under oxygenglucose deprivation," Cellular and Molecular Neurobiology, vol. 33, no. 4, pp. 543-549, 2013.

[64] Z. Balla, B. Hoch, P. Karczewski, and I. E. Blasig, "Calcium/calmodulin-dependent protein kinase $\mathrm{II} \delta_{2}$ and $\gamma$ isoforms regulate potassium currents of rat brain capillary endothelial cells under hypoxic conditions," The Journal of Biological Chemistry, vol. 277, no. 24, pp. 21306-21314, 2002.

[65] K. A. Kenyon, E. A. Bushong, A. S. Mauer, E. E. Strehler, R. J. Weinberg, and A. C. Burette, "Cellular and subcellular localization of the neuron-specific plasma membrane calcium ATPase PMCA1a in the rat brain," The Journal of Comparative Neurology, vol. 518, no. 16, pp. 3169-3183, 2010.
[66] M. Chen, K. G. Lucas, B. F. Akum et al., "A novel role for snapin in dendrite patterning: interaction with cypin," Molecular Biology of the Cell, vol. 16, no. 11, pp. 5103-5114, 2005.

[67] O. Vites, J. S. Rhee, M. Schwarz, C. Rosenmund, and R. Jahn, "Reinvestigation of the role of snapin in neurotransmitter release," The Journal of Biological Chemistry, vol. 279, no. 25, pp. 26251-26256, 2004.

[68] S. Wei, Y. Xu, H. Shi et al., "EHD1 is a synaptic protein that modulates exocytosis through binding to snapin," Molecular and Cellular Neurosciences, vol. 45, no. 4, pp. 418-429, 2010.

[69] F. Deak, O. H. Shin, J. Tang et al., "Rabphilin regulates SNARE-dependent re-priming of synaptic vesicles for fusion," The EMBO Journal, vol. 25, no. 12, pp. 2856-2866, 2006. 